\title{
Strengthening Indigenous Australian Perspectives in Allied Health Education: A Critical Reflection
}

\author{
Danielle Manton, Megan Williams
}

\section{A R T I C LE IN F O}

Keywords:

Indigenous Australians

Allied health

Curriculum

Cultural safety

Cultural responsiveness

https://doi.org/10.32799/ijih.v16i1.33218

\section{A U THOR I NFO}

\begin{abstract}
A B S T R A C T
While professional education in medicine and nursing in Australia has been implementing strategies to increase accessibility for Indigenous Australians, allied health professions remain underdeveloped in this area. Failure to improve the engagement of allied health professions with Indigenous Australians, and failure to increase the numbers of Indigenous staff and students risks perpetuating health inequities, intergenerational disadvantage, and threatens the integrity of professions who have publically committed to achieving cultural safety and health equity between Indigenous and non-Indigenous people. Knowing this, leaders in the allied health professions are asking "What needs to change?" This paper presents a critical reflection on experiences of a university-based Indigenous Health Unit leading the embedding of Indigenous perspectives in allied health curriculum, informed by Indigenous community connections, literature reviews, and research in the context of an emerging community of practice on Indigenous health education. Key themes from reflections are presented in this paper, identifying barriers as well as enablers for change, which include Indigenous community relationship building, education of staff and students, and collaborative research and teaching on Indigenous Peoples' allied health needs and models of care. These enablers are inherently anti-racism strategies that redress negative stereotypes perpetuated about Indigenous Australians and encourage the promotion of valuable Indigenous knowledges, principles, and practices as strategies that may also help meet the health needs of the general community.
\end{abstract}

Danielle Manton, PhD candidate Indigenous Health Discipline, University of Technology Sydney (UTS), Sydney, New South Wales, Australia. Danielle is a Barunggam woman and Teaching Fellow currently designing and implementing teaching and learning opportunities to embed an Indigenous Graduate Attribute across allied health coursework at UTS's Graduate School of Health. Affiliations: Baabayn Aboriginal Corporation; Bimbadeen Christian Training College; The Glen rehabilitation centre; Katungul Aboriginal Corporation Regional Health and Community Services; Gamarada Healing and Life Training; First Peoples Disability Network Australia. Email: Danielle.Manton@uts.edu.au

Megan Williams, PhD, Research Lead and Assistant Director, National Centre for Cultural Competence, University of Sydney. Megan is Wiradjuri and has over 20 years' experience working on programs and research to improve the health of Indigenous people and their families. Megan has led the embedding of Indigenous knowledges across six health master's programs, and contributes to curriculum in social work, journalism, public health, and education. Affiliations: Chair, Human Ethics Review Committee, Justice Health \& Forensic Mental Health Network; Associate Editor, Health Sociology Review; Board Member, Croakey Health Media. 


\section{Glossary}

Allied health: Includes health professionals who are not doctors, nurses, or dentists. Allied health professionals work to prevent, diagnose, treat, and manage illness, disease, and chronic conditions.

Cultural safety: Development of an environment that is spiritually, socially, emotionally, and physically supportive and safe for Indigenous people, and that respects their cultures and identities.

Wholistic health: The social, emotional, psychological, physical, environmental, spiritual, and cultural wellbeing of the whole community, in which individuals are able to flourish across the lifespan and generations.

Indigenous Australians: Aboriginal and Torres Strait Islander Peoples, the original inhabitants and sovereign owners of Australia.

Indigenous Graduate Attribute: University-level requirement for graduates to be responsive to needs and cultures of Indigenous people, relative to their profession.

\section{Acknowledgements}

Maridulu Budyari Gumal, Sydney Partnership for Health, Education, Research, and Enterprise Education Working Party, Liverpool, New South Wales, Australia

Andrew Hayen, Professor of Public Health, Australian Centre for Public and Population Health, University of Technology Sydney

Mark Ragg, Director, Ragg \& Co, Marrickville, New South Wales

Australia Indigenous community partners: Baabayn Aboriginal Corporation; Bimbadeen Christian Training College; The Glen rehabilitation centre; Katungul Aboriginal Corporation Regional Health and Community Services; Gamarada Healing and Life Training; First Peoples Disability Network Australia

\section{Introduction}

Because of their diversity and differing expertise, allied health services can offer much to meet the needs of Indigenous Australians, who currently experience among the worst health outcomes of any of the population groups across urban, regional, and remote locations in Australia (Australian Bureau of Statistics [ABS], 2018) and the world (Anderson et al., 2016). Many of the health issues Indigenous Australians experience are those that are likely to greatly benefit from individual and inter-disciplinary allied health care (Ewen et al., 2019). A person with Type 2 diabetes mellitus, for example, may benefit from allied health care such as podiatry, orthoptics, counselling, and psychology, because of frequent co-morbidities of lower-limb infections and amputation, diabetic retinopathy, and risks of poor mental health and social isolation (Australian Institute of Health and Welfare [AIHW], 2016; Cunningham, 2010; Deroy \& Schütze, 2019).

However, data suggest Indigenous Australians access allied health services less than others in Australia. In 2016, claims made for specialist and allied health services to Australia's 
Medicare Benefits Scheme were 43 percent less for Indigenous Australians compared to others (AIHW, 2016). This is despite the fact that the allied health workforce in Australia is large, making up about a quarter of all health professionals (AIHW, 2014). Further, the workforce is steadily growing and is expected to continue to do so (Department of Health, 2019). However, the number of Indigenous Australians employed as allied health professionals is small and varies greatly across the professions (Williams et al., 2020). Government targets for an Indigenous workforce of 3 percent of the total workforce (NSW Public Service Commission, 2019) have rarely been met (Williams et al., 2020).

This 3 percent Indigenous workforce target reflects the percentage of Indigenous people in the general Australian population (ABS, 2017). This workforce target also acknowledges that allied health professions seek and require growth in the number of Indigenous professionals, and reinforces the role of allied health professions in treatment of health issues, prevention, early intervention and follow-up care, inter-disciplinary referrals, and promotion of self-management (Ah Kit et al., 2003; Bailie et al., 2016; Gibson et al., 2015; Philip, 2015). Allied health professions are known for being diverse, with 23 recognised by New South Wales (NSW) Health, the largest government health policy and service delivery organisation in Australia (Williams et al., 2020). There are many allied health education offerings around Australia, with coursework training accessible in face-to-face and mixed-mode delivery (Williams et al., 2019). Yet questions remain about why Indigenous Australians have such low levels of access to services and such low staff and student numbers.

\section{Methods}

This article is a critical reflection on the low numbers of Indigenous Australians working in, studying, and accessing allied health, informed by the work of two Indigenous Australian university staff members with teaching and research experience in health. To inform the establishment of a new Indigenous Health Unit, woven among six allied health units but autonomous, we conducted a review of international literature pertaining to allied health, Indigenous Peoples, and workforce development. Community consultations were conducted in four regions of the Australian jurisdiction of New South Wales (NSW). NSW is home to the highest number of Indigenous Australians, with 33.3 percent of the Indigenous population of 798,400 people, yet they make up only 3.5 percent of the total NSW population (ABS, 2019). Meetings were held to ascertain Indigenous organisations' interest in collaborating to develop new allied health curriculum. Meetings occurred with Indigenous Elders, service providers, and community members, and were followed by an Expression of Interest process inviting Indigenous community organisations to formally collaborate. Six Indigenous organisations selfnominated to be involved and to form the Indigenous Health Bunya Project (Manton, 2019), a mixed-methods action research project to develop and evaluate new curriculum from an Indigenous perspective.

For a separate government-funded research project we were concurrently undertaking to investigate barriers and enablers for building an Indigenous Australian allied health workforce, 
we conducted three literature reviews. These focused on 1) allied health service delivery related to Indigenous people; 2) Indigenous employment literature, policies, and workforce data; and 3) pathways into allied health education for Indigenous people. These three rounds of literature reviews are synthesised here, along with insights from the Indigenous community consultations.

Our Indigenous Health Unit's andragogy and the framework for adult learning, which was conceptualised to guide curriculum development, is also described. This framework incorporates the Cultural Responsiveness Framework of the national organisation Indigenous Allied Health Australia (IAHA, 2019a), the 8-Ways Aboriginal Pedagogical Framework (Yunkaporta, 2009), and the National Health and Medical Research Council's (NHMRC) ethics guidelines for Aboriginal and Torres Strait Islander health research (NHMRC, 2018) to provide an informed foundation for the Indigenous Health Unit's teaching and research. Our critical reflection on literature, consultations, frameworks, and experiences has followed Kolb's learning cycle (Lisko \& O'dell, 2010), occurring in the context of an emerging community of practice, the Aboriginal Health and Wellbeing Education Working Party of Maridulu Budyari Gumal, a multiinstitutional research translation collaboration (2020). Themes arising from our reflections are presented here to guide future allied health curriculum and workforce development strategies for Indigenous Peoples and allied health professionals more broadly.

\section{Results}

\section{Invisibility of Indigenous Australians in Allied Health}

Literature reviews and community consultations confirmed that Indigenous Australians are relatively invisible in the allied health professions in Australia. Aboriginal Community Controlled Health Organisations (ACCHOs) are the largest providers of health care to Indigenous Peoples in Australia (Australian Institute of Health, 2016); however, allied health care in ACCHOs is minimal, with long waiting lists and limited availability due to funding restrictions, remoteness of service locations, and low number of staff willing to work remotely. Allied health staff in these services are rarely Indigenous people, and Indigenous Australians are seldom reflected in recruitment, advertising, or mentoring programs to grow the allied health workforce (Williams et al., 2019). The evidence base about Indigenous Australians and allied health is small, and that which exists positions Indigenous people as service users, with publications written "about" rather than "by" Indigenous people.

In research reviewing Australian allied health professions' commitments to Indigenous health, only minimal evidence of advocacy, partnerships, and professional development activities was found (Williams et al., 2020). This inactivity generally persists, even though the poor health of Indigenous Australians has been well-reported and responded to by other health disciplines, such as medicine and nursing, as well as by ACCHOs for at least three decades. Allied health professions have only minimal engagement in collective national-level advocacy to improve health equity between Indigenous Peoples and other Australians, such as through the Close the Gap campaign. This campaign stimulated, and also annually independently reviews, the Australian government's Closing the Gap framework, which has seven national targets for 
improvements in Indigenous health (Council of Australian Governments, 2008; Prime Minister and Cabinet, 2019). Few allied health professions have been involved in these national target developments. Further, few allied health professionals include information regarding Indigenous Australians on their websites, and few include Indigenous Australians in their leadership teams or on written communications available to members (Williams et al., 2019). Very little growth in numbers of Indigenous allied health professionals has occurred in the last decade for which NSW data are available. Only four out of 23 allied health professions counted met the 3 percent target, with seven having no Aboriginal and Torres Strait Islander staff (Williams et al., 2020). Overall, in Australia the Indigenous allied health workforce represents less than $0.5 \%$ of the Australian allied health workforce (IAHA, 2018).

\section{Leadership of Allied Health Professionals: Accreditation and Indigenous Graduate Attributes}

Indigenous Australians are also relatively invisible in the accreditation processes of allied health professions. Some professions have developed accreditation standards that incorporate Indigenous Peoples' perspectives into tertiary curriculum and/or professional development (Australian Health Practitioner Regulation Agency, 2019; Australian Pharmacy Council, 2014; Australian Physiotherapy Council, 2017; Australian Psychology Accreditation Council, 2019; Human Genetics Society of Australasia, 2016; Speech Pathology Australia, 2018a, 2018b). These accreditation requirements go some way to recognising Indigenous people as non-Western cultures different from the mainstream Australian population, requiring culturally and socially relevant models of care based on Indigenous leaders' expertise and community need. However, some allied health professions do not require Indigenous perspectives for accreditation, nor do they provide a rationale for this or any other explicit sector, staff, or student development options (Williams et al., 2019).

On the other hand, most Australian tertiary education institutions have committed to including Indigenous Peoples' perspectives or other diverse cultural perspectives in their curriculum (Universities Australia [UA], 2020). University of Technology Sydney, the tertiary institution that is home to this Indigenous allied health project, requires that all graduating students meet an Indigenous Graduate Attribute (IGA). An IGA in this Australian tertiary education context is a short, aspirational statement added to all coursework descriptors and course outlines which indicates that as a result of completing the course, all students will have an improved awareness of Australia's Indigenous cultures (Behrendt et al., 2012; Bodkin-Andrews et al., 2018; Bosanquet et al., 2012; Bullen \& Roberts, 2018; UA, 2011). IGAs are not compulsory for Australian universities to implement (NHMRC, 2018), but of Australia's 40 tertiary institutions, 31 have committed to developing cultural capability among students generally, and 14 routinely report on progress toward meeting an IGA (UA, 2020). Universities with an IGA require coursework-teaching staff to audit their curriculum and identify content and assessment items that could be added to meet the IGA. Usually an IGA requires that all students become culturally aware of and responsive to the needs of communities with whom they may be in contact as professionals (Bath et al., 2004; Bovill, 2017; Durey et al., 2017; Graduate School 
of Health, 2018). IGAs may enable students to develop cross-cultural skills relevant to succeeding in future careers and complementary to knowledge gained throughout their education (Hunt et al., 2015; Page, 2014). Embedding an IGA may facilitate students and staff transferring, adapting, and developing knowledge and skills to engage with diverse Indigenous communities across Australia (Goerke \& Kickett, 2014), using higher education to stimulate positive change in Australian culture and workplaces (Behrendt et al., 2012; Krakouer, 2015; Page et al., 2018; Power et al., 2016; Ryan \& Ryan, 2013).

However, inclusion of Indigenous content in the curriculum is not enough (Fredericks, 2008). The extant literature on transformational learning theory and practice asserts that critical self-reflection, immersion in settings to apply knowledge and practice skills, and feedback from mentors are essential (Huria et al., 2017). In the Australian Indigenous health education context, these types of opportunities for students have rarely been achieved, particularly not in such a way as to support students becoming culturally safe health service providers, nor to improve accessibility of health services (Fitzpatrick et al., 2019). Such immersion opportunities are urgently required, with a concerted and coordinated effort to ensure staff and students are supported in real-world contexts to develop knowledge and skills, and, most importantly, to be supporting and serving community needs and priorities.

\section{Tertiary Aboriginal and Torres Strait Islander Teaching Staff}

In allied health, Indigenous staff are vital to gather, critique, and convey evidence and practice wisdom from culturally relevant perspectives, as well as to make connections to ACCHOs for student placements and provide support for staff and students throughout studies and placement (Lucas et al., 2018; Thackrah et al., 2017). Indigenous Peoples' experiences in Australia, including segregation, assimilation, ongoing social exclusion, and frequent experiences of racism, are sensitive and nuanced issues, and it takes expertise and resources to teach students and health professionals about them. Further, health policy and models of health are complex and require teaching expertise. Models of health require Indigenous Australian perspectives, given that concepts of health are culturally determined and are wholistic (Prime Minister and Cabinet, 2019).

At the same time that students are grappling with new information such as this wholistic health definition, they are often also dealing with concerns about how much they have not known about the poor treatment of Indigenous Australians (Gerrett-Magee, 2006; O'Dowd, 2012; Reynolds, 2000), and questions about their place in perpetuating inequality (Fitzpatrick et al., 2019). These can be considerable blocks to learning that must also be sensitively addressed (Fitzpatrick et al., 2019). However, one shortfall in achieving such sensitive education and in meeting embeddedness of an IGA is that tertiary institutions generally do not meet their targets for Indigenous Australian staff numbers, who are best placed to deliver culturally informed course content and guide curriculum (UA, 2011, 2017).

This is despite Australian government funding for tertiary instructions that requiresthem to have Indigenous employment strategies, appoint senior Indigenous leaders, and implement annual reporting mechanisms to stimulate necessary changes. These requirements have been 
devised to both increase staff numbers and ensure accountability and sustainability of improvements over time (UA, 2017). Other supports for Indigenous staff include mentoring; academic development programs; flexible arrangements such as supporting staff to work from the traditional Country and/or community to which they and their ancestors belong; paid leave to honor culturally significant events such as funerals, ceremonies, and days of observance; and network meetings (Behrendt et al., 2012; Onnis, 2019; Roche et al., 2013).

\section{Upskilling Mainstream Allied Health Professionals}

The low number of Indigenous tertiary education staff puts the onus on the general body of allied health professions' teaching staff to upskill themselves, become confident in conveying quality information about Indigenous Australians' health needs and issues, and adequately address student learning needs. Knowledgeable allied health practitioners are vital—for promoting health, preventing disease, and providing diagnosis, treatment, and management (Gibson et al., 2015). Further, as IAHA (2015) advocates, "It is the responsibility of health service providers to demonstrate culturally responsive leadership, and build governance structures and environments that ensure health professionals are encouraged, expected and able to respond" respectfully to the needs of Indigenous people (p. 8) and the needs of people from a range of cultures (Hawala-Druy \& Hill, 2012).

However, histories of massacres and poisonings of Indigenous Australians, and of land theft by colonisers, can render academic staff and students uncomfortable, as can Indigenous Peoples' cultural practices and assertions for land and human rights. For these reasons, education about the history and culture of Indigenous Australians is often avoided (Yunkaporta \& McGinty, 2009). This risks perpetuating stereotypes and misinformation, and limits progress for Indigenous Peoples (Nakata, 2007). Further, without professional development and training, academics are likely to fear incorporating Indigenous perspectives in their curriculum. Although most academics are experts in their field and may teach with excellence, this expertise does not inherently transfer to the teaching of Indigenous perspectives and knowledge (Nakata, 2007). Learning critical self-reflection is therefore essential, as are developing and adapting critical reflection tools (Jackson Pulver et al., 2019; Lucas et al., 2018), and evaluating teaching and learning strategies to develop the cultural responsiveness of the health workforce (Fitzpatrick et al., 2019).

\section{Terminology Troubles: Is it Cultural Awareness, Competence, Safety, or Other?}

Education about Indigenous Australian cultures suffers from confusion about terminology, and competition between education providers erodes the trust and motivation that organisations might have for accessing training (SPHERE Network, 2019). Some start with "cultural awareness"- basic information-giving that is foundational to further steps (Power et al., 2016; Russell-Mundine, 2017; West et al., 2017). However, this is heavily critiqued as not being robust enough, particularly because it does not require improvements in how people behave or relate (Fredericks \& Thompson, 2010). 
Frequently the term "cultural safety" is named as the ideal (Bin-Sallik, 2003; IAHA, 2019a; Williams, 1999), partly because "safety" is decided by service users (Papps \& Ramsden, 1996) and because it reflects a wholistic definition of health. Cultural safety aims to provide:

An environment that is spiritually, socially and emotionally safe, as well as physically safe for people; where there is no assault, challenge, or denial of their identity, of who they are and what they need. It is about shared respect, shared meaning, shared knowledge, and experience of learning together. (Williams, 1999, p. 213)

Further, cultural safety training has been described as being about empathy, ensuring service providers reflect on their own attitudes and practices to balance power in clientservice provider relationships (Hughes, 2018).

These elements of cultural safety are difficult to make a reality. Cultural safety training has also been criticised for focusing on service delivery, rather than on systemic change required to bring about health equity (IAHA, 2019a).

Others instead assert that cultural responsiveness should be the goal because it includes cultural safety but also addresses broader socio-cultural needs of populations (Carteret, 2010; IAHA, 2019a). Working in a culturally responsive way includes strengthsbased and action-oriented approaches for achieving cultural safety, and also action to increase accessibility of health care, through leadership and good governance. As IAHA (2015) asserts, with cultural responsiveness, "the processes and supportive structures around health service delivery are equally as important as actual health outcome measures when determining the overall effectiveness of health service delivery" (p. 8).

This positions cultural responsiveness as requiring that the social determinants of health be addressed - an action some health service providers argue is not their role, however, given their focus on individual-level clinical care (Jackson Pulver et al., 2019).

\section{Knowledge Hierarchies and Their Limits}

As a result of perceived complexities in developing cultural responsiveness, tertiary teaching staff may choose to meet minimum requirements of university and accreditation mandates (Hennig \& Paetkau, 2018), despite these seldom being developed by Indigenous peoples nor with cultural responsiveness in mind. Indigenous Australians are relatively powerless; it is tertiary institutions that have the history and power to define adequate learning and knowledge (Pease, 2013), asserting a generalised set of facts, which overwhelmingly reflects and reinforces Western science (Pease, 2013), as if it were applicable to all (Greenhalgh et al., 2016). Universities in Australia have existed for no longer than 160 years (UA, 2017), a fraction of the 60,000 years of Indigenous Australian cultural continuity, which is too often overlooked (Dudgeon \& Bray, 2018; Sherwood, 2013).

In the past, perspectives of Indigenous Australians across most levels of education have focused on deficits (Bodkin-Andrews et al., 2018; Hogarth, 2018), with reliance on statistics to 
convey health inequity, mortality rates, and comparisons to other Australians (Brough, 2001). While a realistic picture is required, biomedical and epidemiological data gathered by nonIndigenous people overlook contextual information that would provide a wholistic understanding (Tsey et al., 2019).

Through a deficit lens, negative statistics and problems perpetuate stereotypes and oppressive actions, without commitment to Indigenous Australians' community-driven change (Page et al., 2018). This reinforces the notion that Indigenous Australians as a population all have the same problems and are in need of help from outsiders (Fredericks, 2008). Tertiary students have most often been learning "about" Indigenous communities and culture from an outsider position (Norman, 2014) — which is also likely to reinforce deficit discourse (Nakata, 2007; Norman, 2014) — rather than through authentic voices and connections. The result is a discriminatory system that silences Indigenous Australians' ways of knowing, being, and doing (Hogarth, 2018), minimises opportunities for self-determination to be progressed, and risks assimilation of Indigenous Australian students into the dominant mainstream culture rather than strengthening Indigenous solutions. Invisibility of Indigenous perspectives in allied health curriculum specifically, and in the allied health professions generally, is likely to persist because of the minuscule number of Indigenous allied health professionals. There are still too few Indigenous allied health professionals, or other Indigenous health professionals, with experience, time, or support of supervisors to influence curriculum, development of models of care, and the non-Indigenous staff training required to bring about change (Bailey et al., 2020; Williams et al., 2020).

\section{Community Connections to Bring About Change}

Some tertiary institutions do, however, state that they aim to reflect the communities they are located in (University of Technology Sydney, 2019), and occasionally tertiary staff embedding an IGA have developed local community relationships to enrich student learning and professional practice (Bodkin-Andrews et al., 2018). This is beneficial to Indigenous Australians, who are diverse and have more than 250 nations across Australia (Guilfoyle et al., 2010). Consequently, it is inappropriate for one person or group to represent all communities (Carroll et al., 2015). Through strategic local community connections, relationships can develop, with the value of personal connections role-modelled to staff and students (Gibson et al., 2015).

Research and reflections from medicine and from nursing education highlight that developing cultural responsiveness best occurs as a shared process with Indigenous communities, and that it draws on diverse inputs and voices of community members (Carroll et al., 2015). This shared process is asserted in the United Nations Declaration on the Rights of Indigenous Peoples, which states that communities have the expertise and right to meet their social, cultural, and economic needs (Bretag, 2013; United Nations, 2012; Wiessner, 2009). Self-determination is reinforced by Australian national and state government frameworks that recognise the inherent right of Indigenous Peoples to self-determine health care (Ah Kit et al., 2003; Hunt, 2017). Community engagement is also an ethical principle that shapes decision-making among Indigenous Australians (West et al., 2017) and promotes self-determination (Carroll et al., 2015; 
Hunt, 2017). In self-determining strategies for future health education and care, Indigenous voices carry within them the experience of families and communities over generations, pre- and post-colonisation (Geia et al., 2013). They provide students and staff with an authenticity that is difficult to dismiss (Mills et al., 2018; Norman, 2014). When they are included in teaching and learning, Indigenous voices are to be privileged and central (Fredericks, 2008), not an add-on to dominant Western paradigms (Durey et al., 2017; Fredericks, 2008; Hogarth, 2018; West et al., 2017). This in turn requires Indigenous teaching staff, working in partnership with local communities to promote their realities, needs, and aspirations.

\section{Limitations}

This article is a critical reflection of two Indigenous Australian academics. While reflection followed a process and incorporated three rounds of literature reviews and community consultations, there was a dearth of research-based literature on Indigenous Peoples and allied health to draw on. This article, however, offers an informed perspective, well positioned from within allied health tertiary education and constantly engaging with allied health professionals about overcoming barriers to engaging with Indigenous peoples.

\section{Discussion}

The longstanding rhetoric that Indigenous Australians' poor health is an intractable problem (Hogarth, 2018; Jackson Pulver et al., 2019) is slowly changing. One challenge for the future, however, is ensuring Indigenous voices are embedded in health curriculum, including allied health, which is profoundly underdeveloped compared to other health disciplines. This is arguably more possible now than ever before in Australia, enabled by tertiary institutions' commitments to students achieving IGAs. Speaking with authority to allied health students and helping them achieve IGAs requires knowledge, experience, and authenticity (Bodkin-Andrews et al., 2018). Promoting Indigenous ways of knowing, being, and doing by including Indigenous voices in curriculum provides this authenticity with a relevance that is hard to dismiss (Mills et al., 2018; Norman, 2014).

There are, however, many challenges when working at the "cultural interface"- the space between Indigenous and Western knowledge systems (Nakata, 2007). Navigating these knowledges and worldviews requires advanced skills of Indigenous teaching staff to not only interpret the wide range of information and convey it sensitively to a novice audience of students, but also cope with deficit discourse about Indigenous Peoples.

Unfortunately, there are few Indigenous allied health professionals in Australia, and tertiary institutions rarely meet their Indigenous staff target numbers. However, there are a number of important developments, including an Australian tertiary sector-wide strategy for increasing Indigenous staff and student numbers (UA, 2020), and IAHA's Indigenous allied health workforce development strategy (IAHA, 2018). IAHA's workforce surveys and reflections show improvements among its Indigenous allied health student and professional membership in access to supportive networks and mentoring, development of cultural 
responsiveness of their contexts more generally, and some influence as leaders (IAHA, 2019b, 2019c). Until such time as Indigenous allied health student, professional and academic staff numbers grow, the onus must be on the general body of allied health and teaching staff to be critically reflective and contribute to conveying good information about culturally responsive models of allied health care for Indigenous Australians. However, while tertiary educators may have extensive experience with clinical care, this has generally not rendered them confident with Indigenous Australians. The issue is circular: tertiary education institutions suffer from not being able to employ more Indigenous Australian staff to develop and deliver allied health curriculum given there is a shortage of Indigenous allied health staff, and it is difficult to recruit and retain Indigenous Australians in allied health coursework if the curriculum or institution does not represent their needs, cultures, and aspirations.

One potential circuit breaker is genuine partnerships with Indigenous organisations. This could be achieved through partnerships between Indigenous organisations, Elders, experts, and tertiary institutions, which tertiary institutions are supporting now more than ever through their strategic plans. There is a growing conviction, too, that conveying Indigenous knowledges in allied health curriculum, workforce development, and service delivery has much to offer all communities (IAHA, 2015), because Indigenous health is wholistic and draws on fundamental interpersonal skills such as respect, engagement, and shared responsibility for making progress (Berglund \& McNeill, 1989; NHMRC, 2018) — all of which align with the aspirations of the allied health professions.

\section{Conclusion}

It is perhaps only when Indigenous Australians' ways of knowing, being, and doing are recognised for their intrinsic value that they may inform and influence mainstream teaching and service delivery, thereby contributing to achieving health equity. Until then, concerted effort is required to bring the current and next generations of allied health professionals to a standard at which they are confident engaging with Indigenous Australians. One strategy for this is developing partnerships between tertiary institutions and Indigenous organisations that are mutually beneficial: identifying needs of local Indigenous communities and designing curriculum that develops service providers of the future who are able to assist in meeting these needs. An extension of that is advocating for Indigenous Peoples' health rights within curriculum, and providing evidence about Indigenous people's self-determined models of health care. These are inherently anti-racism strategies that redress negative stereotypes perpetuated about Indigenous Australians and enable the promotion of valuable Indigenous knowledges, principles, and practices as strategies to meet community care priorities and standards. These connected health service provider actions will contribute to transformational change required to improve health equity, because it is intergenerational change - tertiary-level training strategies will result in the next generations of health service providers being arguably more prepared than current and previous generations. 


\section{References}

Ah Kit, J., Prideaux, C., Harvey, P., Collins, J., Battersby, M., Mills, P., \& Dansie, S. (2003). Chronic disease self-management in Aboriginal communities: Towards a sustainable program of care in rural communities. Australian Journal of Primary Health, 9(3), 168176. https://doi.org/10.1071/py03043

Anderson, I., Robson, B., Connolly, M., Al-Yaman, F., Bjertness, E., King, A., Tynan, M., Madden, R., Bang, A., Coimbra, C. E. A., Jr., Pesantes, M.A., Amigo, H., Andronov, S., Armien, B., Ayala Obando, D., Axelsson, P., Bhatti, Z. S., Bhutta, Z. A., Bjerregaard, P., ... Yap, L. (2016). Indigenous and tribal peoples' health (The Lancet-Lowitja Institute Global Collaboration): A population study. The Lancet, 388(10040), 131-157. https://doi.org/10.1016/S0140-6736(16)00345-7

Australian Bureau of Statistics. (2017, June 27). 2016 census shows growing Aboriginal and Torres Strait Islander population [Media release]. https://www.abs.gov.au/ausstats/abs@.nsf/MediaRealesesByCatalogue/02D50FAA9987 D6B7CA25814800087E03

Australian Bureau of Statistics. (2018). Life tables for Aboriginal and Torres Strait Islander Australians, 2015-2017. https://www.abs.gov.au/statistics/people/aboriginal-and-torresstrait-islander-peoples/life-tables-aboriginal-and-torres-strait-islander-australians/latestrelease

Australian Bureau of Statistics. (2019). Estimates and projections, Aboriginal and Torres Strait Islander Australians. https://www.abs.gov.au/statistics/people/aboriginal-and-torresstrait-islander-peoples/estimates-and-projections-aboriginal-and-torres-strait-islanderaustralians/latest-release\#states-and-territories

Australian Health Practitioner Regulation Agency. (2019). Registration standards. https://www.ahpra.gov.au/Registration/Registration-Standards.aspx

Australian Human Rights Commission (2013). Indigenous international rights. https://www.humanrights.gov.au/our-work/aboriginal-and-torres-strait-islander-socialjustice/indigenous-international-rights

Australian Institute of Health. (2016). Indigenous Australians' access to health services (No. 15; pp. 1-6). Canberra: Australian Government.

Australian Institute of Health and Welfare. (2014). The size and causes of the Indigenous health gap. In Australia's health 2014: The 14th biennial welfare report of the Australian Institute of Health and Welfare (pp. 1-11). https://www.aihw.gov.au/getmedia/785f924a85f4-4ca0-9dad-1abe0152c14c/7_8-indigenous-health-gap.pdf.aspx

Australian Institute of Health and Welfare. (2016). Australian burden of disease study: Impact and causes of illness and death in Aboriginal and Torres Strait Islander people. http://www.aihw.gov.au/publication-detail/?id=60129557110

Australian Pharmacy Council. (2014). Accreditation standards for pharmacy programs in Australia and New Zealand.

https://apcwebsite.blob.core.windows.net/webfiles/4d4b8bc52eb0ea11a812000d3a6aa9f7 /standards_evidenceguide2014.pdf?sv=2015-07- 
08\&sr=b\&sig=r8\%2Bw4szgdawWE9NxcMG\%2B1ygYaIv6mFqC1hfk12N337U\%3D\&s $\mathrm{e}=2021-01-03 \mathrm{~T} 05 \% 3 \mathrm{~A} 33 \% 3 \mathrm{~A} 26 \mathrm{Z} \& \mathrm{sp}=\mathrm{r}$

Australian Physiotherapy Council. (2017). Guidesline for accreditation: Entry-level physiotherapy practitioner programs of study. https://physiocouncil.com.au/wpcontent/uploads/2017/10/GUIDELINES-FOR-ACCREDITATION-V1.2-18052018.pdf

Australian Psychology Accreditation Council. (2019, January). Accreditation standards for psychology programs.

https://www.psychologycouncil.org.au/sites/default/files/public/Standards_20180912_Pu blished_Final_v1.2.pdf

Bailey, J., Blignault, I., Carriage, C., Demassi, K., Joseph, T., Kelleher, K., Lew Fatt, E., Meyer, L., Naden, P., Nathan, S., Newman, J., Renata, P., Ridoutt, L., Stanford, D., \& Williams, M. (2020). We are working for our people: Growing and strengthening the Aboriginal and Torres Strait Islander health workforce. Melbourne: Lowitja Institute. https://www.lowitja.org.au/content/Image/Career_Pathways_Report_Working_for_Our_ People_2020.pdf

Bailie, C., Matthews, V., Bailie, J., Burgess, P., Copley, K., Kennedy, C., Moore, L., Larkins, S., Thompson, S., \& Bailie, R. S. (2016). Determinants and gaps in preventive care delivery for Indigenous Australians: A cross-sectional analysis. Frontiers in Public Health, 4. https://doi.org/10.3389/fpubh.2016.00034

Bath, D., Smith, C., Stein, S., \& Swann, R. (2004). Beyond mapping and embedding graduate attributes: Bringing together quality assurance and action learning to create a validated and living curriculum. Higher Education Research \& Development, 23(3), 313-328. https://doi.org/10.1080/0729436042000235427

Behrendt, L., Larkin, S., Griew, R., \& Kelly, P. (2012). Review of higher education access and outcomes for Aboriginal and Torres Strait Islander people: Final report. https://docs.education.gov.au/system/files/doc/other/heaccessandoutcomesforaboriginala ndtorresstraitislanderfinalreport.pdf

Berglund, C. A., \& McNeill, P. M. (1989). Guidelines for research practice in Australia: NHMRC statement and professional codes. Community Health Studies, 13(2), 121-129. https://doi.org/10.1111/j.1753-6405.1989.tb00188.x

Bin-Sallik, M. (2003). Cultural safety: Let's name it! The Australian Journal of Indigenous Education, 32, 21-28. https://doi.org/10.1017/S1326011100003793

Bodkin-Andrews, G., Page, S., \& Trudgett, M. (2018). Shaming the silences: Indigenous graduate attributes and the privileging of Aboriginal and Torres Strait Islander voices. Critical Studies in Education, 1-18. https://doi.org/10.1080/17508487.2018.1553795

Bosanquet, A., Winchester-Seeto, T., \& Rowe, A. (2012). Social inclusion, graduate attributes and higher education curriculum. Journal of Academic Language and Learning, 6(2), A73-A87.

Bovill, M. (2017). Winhanga-duri-nya (to reflect). The Medical Journal of Australia, 207(11), 472-473. https://doi.org/10.5694/mja17.00678 
Brough, M. (2001). Healthy imaginations: A social history of the epidemiology of Aboriginal and Torres Strait Islander health. Medical Anthropology, 20(1), 65-90. https://doi.org/10.1080/01459740.2001.9966187

Bullen, J., \& Roberts, L. (2018). Transformative learning: A precursor to preparing health science students to work in Indigenous health settings? The Australian Journal of Indigenous Education, 1-12. https://doi.org/10.1017/jie.2018.3

Carroll, V., Reeve, C. A., Humphreys, J. S., Wakerman, J., \& Carter, M. (2015). Re-orienting a remote acute care model towards a primary health care approach: Key enablers. Rural and Remote Health, 15(3). http://www.rrh.org.au/publishedarticles/article_print_2942.pdf

Carteret, M. (2010, October 19). Culturally responsive care. Retrieved from Dimensions of Culture website, http://www.dimensionsofculture.com/2010/10/576/

Council of Australian Governments. (2008). National Indigenous reform agreement (Closing the gap). Retrieved from http://www.federalfinancialrelations.gov.au/content/npa/health/_archive/indigenousreform/national-agreement_sept_12.pdf

Cunningham, C. (2010). Health of Indigenous peoples. BMJ Open, 340(c1840). https://doi.org/10.1136/bmj.c1840

Department of Health. (2019). Health workforce data summary statistics. Australian Government. https://hwd.health.gov.au/summary.html

Deroy, S., \& Schütze, H. (2019). Factors supporting retention of Aboriginal health and wellbeing staff in Aboriginal health services: A comprehensive review of the literature. International Journal for Equity in Health, 18(1), 70. https://doi.org/10.1186/s12939019-0968-4

Dudgeon, P., \& Bray, A. (2018). Indigenous healing practices in Australia. Women \& Therapy, 41(1-2), 97-113. https://doi.org/10.1080/02703149.2017.1324191

Durey, A., Taylor, K., Bessarab, D., Kickett, M., Jones, S., Hoffman, J., Flavell, H., \& Scott, K. (2017). "Working together": An intercultural academic leadership programme to build health science educators' capacity to teach Indigenous health and culture. The Australian Journal of Indigenous Education, 46(1), 12-22. https://doi.org/10.1017/jie.2016.15

Ewen, S. C., Ryan, T., \& Platania-Phung, C. (2019). Capacity building of the Australian Aboriginal and Torres Strait Islander health researcher workforce: A narrative review. Human Resources for Health, 17(1), 10. https://doi.org/10.1186/s12960-019-0344-X

Fitzpatrick, S., Haswell, M., Williams, M., Nathan, S., \& Meyer, L. (2019). Learning about Aboriginal health and wellbeing at the postgraduate level: Novel application of the Growth and Empowerment Measure. Rural and Remote Health, 19(2). https://doi.org/10.22605/RRH4708

Fredericks, B. (2008). The need to extend beyond the knowledge gained in cross-cultural awareness training. The Australian Journal of Indigenous Education, 37(S1), 81-89. https://doi.org/10.1375/S1326011100000405 
Fredericks, B., \& Thompson, M. (2010). Collaborative voices: Ongoing reflections on cultural competency and the health care of Australian Indigenous people. Journal of Australian Indigenous Issues, 13(3), 10-20.

Geia, L. K., Hayes, B., \& Usher, K. (2013). Yarning/Aboriginal storytelling: Towards an understanding of an Indigenous perspective and its implications for research practice. Contemporary Nurse, 46(1), 13-17. https://doi.org/10.5172/conu.2013.46.1.13

Gerrett-Magee, R. (2006). Discomfort: The university student and Indigenous Peoples. The Australian Community Psychologist, 18(1), 28-32.

Gibson, O., Lisy, K., Davy, C., Aromataris, E., Kite, E., Lockwood, C., Riitano, D., McBride, K., \& Brown, A. (2015). Enablers and barriers to the implementation of primary health care interventions for Indigenous people with chronic diseases: A systematic review. Implementation Science, 10(1), 71. https://doi.org/10.1186/s13012-015-0261-X

Goerke, V., \& Kickett, M. (2013). Working towards the assurance of graduate attributes for Indigenous cultural competency: The case for alignment between policy, professional development and curriculum processes. International Education Journal: Comparative Perspectives, 12(1), 61-81. http://openjournals.library.usyd.edu.au/index.php/IEJ/article/view/7438/7794

Graduate School of Health, University of Technology, Sydney. (2018). Indigenous graduate attributes. https://www.uts.edu.au/about/graduate-school-health/indigenoushealth/learning-and-teaching/indigenous-graduate-attributes

Greenhalgh, T., Jackson, C., Shaw, S., \& Janamian, T. (2016). Achieving research impact through co-creation in community-based health services: Literature review and case study. The Milbank Quarterly, 94(2), 392-429. https://doi.org/10.1111/1468-0009.12197

Guilfoyle, A., Saggers, S., Sims, M., \& Hutchins, T. (2010). Culturally strong childcare programs for Indigenous children, families and communities. Australasian Journal of Early Childhood, 35(3), 68-76. https://doi.org/10.1177/183693911003500309

Hawala-Druy, S., \& Hill, M. H. (2012). Interdisciplinary: Cultural competency and culturally congruent education for millennials in health professions. Nurse Education Today, 32(7), 772-778. https://doi.org/10.1016/j.nedt.2012.05.002

Hennig, C., \& Paetkau, J. (2018, September 6). “Am I colonizing this curriculum?” Teachers share challenges of getting new Indigenous curriculum right. CBC News. https://www.cbc.ca/news/canada/british-columbia/beyond-beads-and-bannock-teachersindigenous-curriculum-1.4811699

Hogarth, M. (2018). Talkin' bout a revolution: The call for transformation and reform in Indigenous education. The Australian Educational Researcher, 45(5), 663-674. https://doi.org/10.1007/s13384-018-0277-8

Hughes, M. (2018). Cultural safety requires “cultural intelligence.” Kai Tiaki Nursing New Zealand, 24(6), 24-25. https://search.proquest.com/openview/cf25f9406d41c4867b957f11d03fc05e/1?pqorigsite $=$ gscholar $\& \mathrm{cbl}=856343$ 
Human Genetics Society of Australasia. (2016, October). Guidelines for training and certification in genetic counselling. Retrieved from https://www.hgsa.org.au/documents/item/59

Hunt, J. (2017). Self-determination. In Aboriginal Affairs NSW (Ed.), Transforming the relationship between Aboriginal peoples and the NSW Government: Aboriginal Affairs NSW research agenda 2018-2023 (pp. 82-93). www.aboriginalaffairs.nsw.gov.au/newknowledge/whats-happening-now/research-agenda/

Hunt, L., Ramjan, L., McDonald, G., Koch, J., Baird, D., \& Salamonson, Y. (2015). Nursing students' perspectives of the health and healthcare issues of Australian Indigenous people. Nurse Education Today, 35(3), 461-467. https://doi.org/10.1016/j.nedt.2014.11.019

Huria, T., Palmer, S., Beckert, L., Lacey, C., \& Pitama, S. (2017). Indigenous health: Designing a clinical orientation program valued by learners. BMC Medical Education, 17(1), 180. https://doi.org/10.1186/s12909-017-1019-8

Indigenous Allied Health Association. (2015). Cultural responsiveness in action: An IAHA framework. https://iaha.com.au/workforce-support/training-and-development/culturalresponsiveness-in-action-training/

Indigenous Allied Health Association. (2018). Workforce development strategy 2018-2020. http://iaha.com.au/wp-content/uploads/2018/02/IAHA_WFD2018_WEB.pdf

Indigenous Allied Health Association. (2019a). Cultural responsiveness in action: An IAHA framework. https://iaha.com.au/iaha-consulting/cultural-responsiveness-training/

Indigenous Allied Health Association. (2019b). Leaving healthy footprints. Canberra: IAHA.

Indigenous Allied Health Association. (2019c). Panel: IAHA 10 years: Strengths, solutions and self determination [Video]. 2019 IAHA conference panel discussion. YouTube. https://www.youtube.com/watch?v=5h4P3CWGCEg

Jackson Pulver, L., Williams, M., \& Fitzpatrick, S. (2019). Social determinants of Australia's First Peoples' health: A multi-level empowerment perspective. In P. Liamputtong (Ed.), Social determinants of health (pp. 175-214). Melbourne: Oxford University Press Australia.

Krakouer, J. (2015). Literature review relating to the current context and discourse on Indigenous cultural awareness in the teaching space: Critical pedagogies and improving Indigenous learning outcomes through cultural responsiveness. Australian Council for Educational Research. https://research.acer.edu.au/cgi/viewcontent.cgi?article=1043\&context=indigenous_educ ation

Lisko, S. A., \& O’Dell, V. (2010). Integration of theory and practice: Experiential learning theory and nursing education. Nursing Education Perspectives, 31(2), 106. https://journals.lww.com/neponline/Abstract/2010/03000/Integration_of_Theory_and_Pr actice_Experiential.10.aspx

Lucas, C., Williams, K., Tudball, J., \& Walpola, R. L. (2018). Community, hospital and industry preceptor perceptions of their role in experiential placements-The need for 
standardization of preceptor responsibilities and evaluations on students. Currents in Pharmacy Teaching and Learning, 10(11), 1447-1455. http://hdl.handle.net/10453/128956

Manton, D. (2019). The Bunya Project: Development and evaluation of the Graduate School of Health curriculum. Australian Institute of Aboriginal and Torres Strait Islander Studies.

Maridulu Budyari Gumal. (2020). Working together for good health and wellbeing. https://www.thesphere.com.au

Mills, K., Creedy, D. K., \& West, R. (2018). Experiences and outcomes of health professional students undertaking education on Indigenous health: A systematic integrative literature review. Nurse Education Today, 69, 149-158. https://doi.org/10.1016/j.nedt.2018.07.014

Nakata, M. (2007). Disciplining the savages: Savaging the disciplines. Canberra: Aboriginal Studies Press.

National Health and Medical Research Council. (2018). Keeping research on track II: A companion document to Ethical conduct in research with Aboriginal and Torres Strait Islander Peoples and communities: Guidelines for researchers and stakeholders. Retrieved from https://www.nhmrc.gov.au/about-us/resources/ethical-conduct-researchaboriginal-and-torres-strait-islander-peoples-and-communities

Norman, H. (2014). Mapping more than Aboriginal studies: Pedagogy, professional practice and knowledge. The Australian Journal of Indigenous Education, 43(1), 42-51. https://doi.org/10.1017/jie.2014.6

NSW Public Service Commission. (2019). NSW Working together for a better future 2019-2025. https://www.psc.nsw.gov.au/ArticleDocuments/4433/Aboriginal-Employment-Strategy2019-2025.pdf.aspx

O’Dowd, M. (2012). Engaging non-Indigenous students in Indigenous history and "un-history": An approach for non-Indigenous teachers and a politics for the twenty-first century. History of Education Review, 41(2), 15. https://doi.org/10.1108/08198691211269539

Onnis, L. (2019). HRM and remote health workforce sustainability: The influence of localised management policies. Singapore: Springer.

Page, S. (2014). Exploring new conceptualisations of old problems: Researching and reorienting teaching in Indigenous studies to transform student learning. The Australian Journal of Indigenous Education, 43(1), 21-30. https://doi.org/10.1017/jie.2014.4

Page, S., Trudgett, M., \& Bodkin-Andrews, G. (2018). Creating a degree-focused pedagogical framework to guide Indigenous graduate attribute curriculum development. Higher Education, 78, 1-15. https://doi.org/10.1007/s10734-018-0324-4

Papps, E., \& Ramsden, I. (1996). Cultural safety in nursing: The New Zealand experience. International Journal for Quality in Health Care, 8(5), 491-497. https://doi.org/10.1093/intqhc/8.5.491

Pease, B. (2013). Undoing privilege: Unearned advantage in a divided world. London: Zed Books. 
Philip, K. (2015). Allied health: Untapped potential in the Australian health system. Australian Health Review, 39(3), 244-247. https://doi.org/10.1071/AH14194

Power, T., Virdun, C., Sherwood, J., Parker, N., Van Balen, J., Gray, J., \& Jackson, D. (2016). REM: A collaborative framework for building Indigenous cultural competence. Journal of Transcultural Nursing, 27(5), 439-446. https://doi.org/10.1177/1043659615587589

Prime Minister and Cabinet. (2019). Closing the gap report 2019. https://www.niaa.gov.au/resource-centre/indigenous-affairs/closing-gap-prime-ministersreport-2019

Reynolds, H. (2000). Why weren't we told? A personal search for the truth about our history. Melbourne: Penguin.

Roche, A. M., Duraisingam, V., Trifonoff, A., Battams, S., Freeman, T., Tovell, A., Weetra, D., $\&$ Bates, N. (2013). Sharing Stories: Indigenous alcohol and other drug workers' wellbeing, stress and burnout. Drug and Alcohol Review, 32, 527-535.

doi:10.1111/dar.12053

Russell-Mundine, G. (2017). The cultural capability of New South Wales public servants. In Aboriginal Affairs NSW (Ed.), Transforming the relationship between Aboriginal peoples and the NSW Government: Aboriginal Affairs NSW research agenda 2018-2023 (p. 122). www.aboriginalaffairs.nsw.gov.au/new-knowledge/whats-happeningnow/research-agenda/

Ryan, M., \& Ryan, M. (2013). Theorising a model for teaching and assessing reflective learning in higher education. Higher Education Research \& Development, 32(2), 244-257. https://doi.org/10.1080/07294360.2012.661704

Sherwood, J. (2013). Colonisation - It's bad for your health: The context of Aboriginal health. Contemporary Nurse, 46(1), 28-40. https://doi.org/10.5172/conu.2013.46.1.28

Speech Pathology Australia. (2018a). Accreditation of speech pathology degree programs. https://www.speechpathologyaustralia.org.au/SPAweb/Resources_for_the_Public/Univer sity_Programs/Accreditation_Process/SPAweb/Resources_for_the_Public/University_Pr ograms/Process.aspx?hkey=0917ee72-6b04-4479-9f51-7c7b89926539

Speech Pathology Australia. (2018b). Accreditation of speech pathology degree programs: Guidelines for reporting of Aboriginal and Torres Strait Islander curriculum development and inclusions. https://www.speechpathologyaustralia.org.au/SPAweb/Resources_for_the_Public/Univer sity_Programs/Accreditation_Process/SPAweb/Resources_for_the_Public/University_Pr ograms/Process.aspx?hkey=0917ee72-6b04-4479-9f51-7c7b89926539

SPHERE Network. (2019). Maridulu Budyari Gumal: Aboriginal health and wellbeing. http://www.thesphere.com.au/work/aboriginal-health-and-wellbeing

Thackrah, R. D., Hall, M., Fitzgerald, K., \& Thompson, S. C. (2017). Up close and real: Living and learning in a remote community builds students' cultural capabilities and understanding of health disparities. International Journal for Equity in Health, 16(1), 119. https://doi.org/10.1186/s12939-017-0615-X 
Tsey, K., Onnis, L., Whiteside, M., McCalman, J., Williams, M., Heyeres, M., Lui, S. M. (C.), Klieve, H., Cadet-James, Y., Baird, L., Brown, C., Watkin Lui, F., Grainger, D., Gabriel, Z., Millgate, N., Cheniart, B., Tahalani, H., Liu, H.-B., Yinghong, Y., ... Kinchin, I. (2019). Assessing research impact: Australian Research Council criteria and the case of Family Wellbeing research. Evaluation and Program Planning, 73, 176-186. https://doi.org/10.1016/j.evalprogplan.2019.01.004

United Nations. (2012, December 14). UN declaration on the rights of Indigenous Peoples. Retrieved from https://www.un.org/development/desa/indigenouspeoples/wpcontent/uploads/sites/19/2018/11/UNDRIP_E_web.pdf

Universities Australia. (2011). National best practice framework for Indigenous cultural competency in Australian universities. https://www.universitiesaustralia.edu.au/wpcontent/uploads/2019/06/National-Best-Practice-Framework-for-Indigenous-CulturalCompetency-in-Australian-Universities.pdf

Universities Australia. (2017). Indigenous strategy 2017-2020. https://www.universitiesaustralia.edu.au/wp-content/uploads/2019/06/IndigenousStrategy-2019.pdf

Universities Australia. (2020). Indigenous strategy second annual report. Canberra: Universities Australia. Retrieved from https://www.universitiesaustralia.edu.au/wpcontent/uploads/2020/02/Indigenous-strategy-second-annual-report.pdf

University of Technology Sydney. (2019). UTS 2027 strategy. https://www.uts.edu.au/about/uts2027-strategy

West, R., Wrigley, S., Mills, K., Taylor, K., Rowland, D., \& Creedy, D. K. (2017). Development of a First Peoples-led cultural capability measurement tool: A pilot study with midwifery students. Women and Birth, 30(3), 236-244. https://doi.org/10.1016/j.wombi.2017.01.004

Wiessner, S. (2009). The United Nations declaration on the rights of Indigenous Peoples. In A. Constantinides \& N. Zaikos (Eds.), The diversity of international law (343-362). Brill/Nijhoff. https://doi.org/10.1163/ej.9789004180390.i-676

Williams, R. (1999). Cultural safety-What does it mean for our work practice? Australian and New Zealand Journal of Public Health, 23(2), 213-214. https://doi.org/10.1111/j.1467842X.1999.tb01240.x

Williams, M., Ragg, M., \& Manton, D. (2019). Aboriginal allied health workforce pathways: Education pathways [Submitted for Publication] Graduate School of Health, University of Technology Sydney.

Williams, M., Ragg, M., \& Manton, D. (2020). Aboriginal allied health workforce pathways scoping project: Final report. [Submitted for Publication]. Graduate School of Health, University of Technology Sydney.

Yunkaporta, T. (2009). Aboriginal pedagogies at the cultural interface [Doctoral dissertation, James Cook University, Cairns, Australia]. ResearchOnline@ JCU. http://eprints.jcu.edu.au/10974 
Yunkaporta, T., \& McGinty, S. (2009). Reclaiming Aboriginal knowledge at the cultural interface. The Australian Educational Researcher, 36(2), 55-72.

https://doi.org/10.1007/BF03216899 